OPEN ACCESS

Edited by:

Shourong Shi,

Poultry Institute, Chinese Academy of Agricultural Sciences (CAAS), China

Reviewed by:

Yang Zhi,

Yangzhou University, China

Kai Qiu,

Chinese Academy of Agricultural Sciences (CAAS), China

*Correspondence:

Aiwei Guo

g.aiwei.swfu@hotmail.com

Specialty section: This article was submitted to Animal Nutrition and Metabolism, a section of the journal Frontiers in Veterinary Science

Received: 28 October 2021 Accepted: 08 December 2021

Published: 10 January 2022

Citation:

Tong Z, He W, Fan X and Guo A (2022) Biological Function of Plant

Tannin and Its Application in Animal Health. Front. Vet. Sci. 8:803657. doi: 10.3389/fvets.2021.803657

\section{Biological Function of Plant Tannin and Its Application in Animal Health}

\author{
Zhenkai Tong, Wenfeng He, Xiao Fan and Aiwei Guo* \\ Faculty of Life Sciences, Southwest Forestry University, Kunming, China
}

Plant tannins are widely found in plants and can be divided into hydrolyzed tannins and condensed tannins. In recent years, researchers have become more and more interested in using tannin-rich plants and plant extracts in ruminant diets to improve the quality of animal products. Some research results show that plant tannins can effectively improve the quality of meat and milk, and enhance the oxidative stability of the product. In this paper, the classification and extraction sources of plant tannins are reviewed, as well as the biological functions of plant tannins in animals. The antioxidant function of plant tannins is discussed, and the influence of their structure on antioxidation is analyzed. The effects of plant tannins against pathogenic bacteria and the mechanism of action are discussed, and the relationship between antibacterial action and antioxidant action is analyzed. The inhibitory effect of plant tannins on many kinds of pathogenic viruses and their action pathways are discussed, as are the antiparasitic properties of plant tannins. The anti-inflammatory action of tannins and its mechanism are analyzed. The function of plant tannins in antidiarrheal action and its influencing factors are discussed. In addition, the effects of plant tannins as feed additives on animals and the influencing factors are reviewed in this paper to provide a reference for further research.

Keywords: plant tannins, classification, biological function, application, extraction source

\section{INTRODUCTION}

Plant tannins are polyphenols that are widely found in terrestrial plants and in some marine plants (phloroglucinol). Plant tannins have been used as additives in animal production for many years (1). They may affect metabolism or the gut microbiota $(2,3)$, with the aim of improving performance or meat quality (4). Patra and Saxena (5) showed that plant tannins can improve feed efficiency and animal health. Aboagye et al. (6) found that plant tannins have a strong affinity for protein, and the appropriate addition of plant tannins to ruminant has nutritional value. In contrast, it is believed that the addition of a high concentration of plant tannins to the diets of single-stomached animals will cause adverse effects such as reduced nutrient availability and performance of animals $(7,8)$. Schiavone et al. (9) also demonstrated that adding $0.20 \%$ plant tannins to the broiler diet can increase feed intake and average daily gain, while $0.25 \%$ tannins has a negative impact on broiler performance. It can be concluded that plant tannins have enormous potential as feed additives (10-12). However, plant tannins are complex substances whose beneficial and harmful properties depend on their chemical structure, the concentration and other factors. Therefore, this paper reviewed the classification, extraction sources and biological functions 
of plant tannins, as well as the factors influencing the additive effect, providing a reference for further research.

\section{CLASSIFICATION AND SOURCES OF PLANT TANNINS}

\section{Classification of Plant Tannins}

The chemical structures of plant tannins are diverse, and systematic classification of tannins based on specific structural characteristics and chemical properties can provide a convenient framework for related research. Plant tannins can be broadly divided into hydrolyzed tannins and condensed tannins. Hydrolyzed tannins consist of polyphenol nuclei with molecular weights ranging from 500 to 3,000 Daltons (Da) (13). Condensed tannins are oligomeric or polymeric flavonoids composed of flavane-3-ols, including catechin, epicatechin, gallocatechin, and epigallocatechin. Their molecular weights vary from 1,000 to $20,000 \mathrm{Da}$, they depolymerize only with strong oxidation and acid, and they are not easily degraded by anaerobic enzymes (14).

Plant tannins can be broadly divided into two categories, which are relatively general. There are ellagic tannins and polyol residues that cannot be completely hydrolyzed in hydrolyzed tannins (15), but they are divided into hydrolyzed tannins. Hydrolyzed tannins were first described as containing the Cglycoside catechin in addition to the characteristic structure of monomer ellagins in 1985 (16). At first, it was unscientific to classify these plant tannins into hydrolyzed tannins because C-Ccoupled catechin structures contained some glycosides, and only some structures could be hydrolyzed (17). Therefore, tannins were further classified into four major categories according to their chemical structure: gallotannins refer to the combination of galloyl groups or their derivatives with polyols, catechins or triterpenoids; ellagitannins refer to at least two gallic CCs conjugated to each other and catechins conjugated without glycoside; compound tannins refer to glucogenated catechins in addition to gallic tannins or ellagic tannins and condensed tannins mean that C-4 of catechin is linked to C-8 or C-6 of another catechin unit to form oligomer procyanidins and polymeric procyanidins (18).

\section{Extraction Sources of Plant Tannin}

Plant tannins are widely distributed in the plant kingdom, especially in herbages, shrubs, cereals and medicinal materials (19). They are also found in many fruits, such as bananas, blackberries, apples and grapes (20-23). Complex tannins and condensed tannins are the most common and easy to extract from legumes, trees and shrubs; Gallic tannins are commonly found in gallnuts, lacquer leaves and cotinus leaves, while ellagic tannins are commonly found in oaks, blackberries and pomegranates. Plant tannins are more abundant in vulnerable parts of plants, such as new leaves and flowers (24). Because the chemical structure and content of plant tannins vary greatly among different plant species, growth stages and growth conditions (such as temperature, light, and nutrients), the biological functions of different extraction sources vary $(25,26)$.

\section{BIOLOGICAL FUNCTIONS AND INFLUENCING FACTORS OF PLANT TANNINS}

\section{Antioxidant Activity}

The antioxidant properties of tannins are widely utilized in the food and medical fields. In recent years, many studies have been conducted to identify the relevant antioxidant activity of tannins. Owing to its antioxidant capacity, such as preventing cardiovascular disease, cancer or osteoporosis, tannins have attracted much attention $(27,28)$. In a study by Phung et al., the extracts of Japanese chestnut exhibited the most remarkable DPPH-scavenging capacity. The results suggested that as a potential natural preservative agent, tannins provided promising antioxidant capacities (29). A study determined the effects of the forage conservation method and condensed tannins (CT) from conserved forage on rumen fermentation and showed that CT from purple prairie clover (PPC) decreased protein degradation in vitro but had minimal effects on overall rumen fermentation (30). CT from the leaves of $F$. altissima was also indicated to express superior antioxidant capacity (31).

At present, plant tannins have been proven to have antioxidant properties in different animals. A study in mutton showed that the color stability of the longissimus dorsi muscle (LM) was extended by tannin supplementation, with lower changes in the hue angle in the treatment groups than in the control groups (32). In Rex rabbits, adding tannic acid to the diet significantly increased the activity of serum total superoxide dismutase (T-SOD) and decreased the malondialdehyde (MDA) content (33). Similar results were also demonstrated in broiler chickens. Grape seed extracts (GSEs), which contain tannins, significantly decreased serum total cholesterol, low-density lipoprotein cholesterol and meat malondialdehyde levels. GSEs also increased the antibody titer against the Newcastle disease virus vaccine (34).

To date, the mechanism of tannin antioxidant activity may remain unclear about the exact underlying mechanism involved. Some researchers have argued that the higher the relative molecular weight is, the stronger the antioxidant activity of tannins (35). The ability to scavenge free radicals depends on the number and polymerization degree of hydroxyl groups. The more hydroxyl groups in plant tannins, the more easily they can be oxidized; thus, tannins have higher antioxidant activity $(36,37)$. Gallic tannins are easily degraded in the gastrointestinal tract, while condensed tannins are difficult to degrade and absorb in the gastrointestinal tract. Therefore, it is difficult to explain the antioxidant performance of plant tannins in animals as a whole. The quebracho tannins were not digested and absorbed in the gastrointestinal tract but increased the antioxidant capacity of sheep liver and plasma, indicating that condensed tannins may indirectly affect the antioxidant function of animals (38). Some researchers also believe that condensed tannins form a protective film in the stomach by complexing with other molecules to protect the gastrointestinal tract and its contents from oxidation (39). Literature reviewed so far tends to demonstrate that the antioxidant function of plant tannins are mainly linked to their chemical structure rather than the extraction source (plant 
spp.). In addition, the specific antioxidant mechanism of plant tannins in animal tissues has not completely clarified, and further research is needed.

\section{Antibacterial Activity}

As natural polyphenolic compounds, tannins display antibacterial effects. Research has investigated the effects of different levels of tannins on growth performance, intestinal microorganisms and morphology in piglets. A study found that tannins at $0.13,2.25$, and $0.45 \%$ significantly improved the feed conversion rate, reduced the concentrations of ammonia, isobutyric, and isovaleric acid in the cecum, decreased the depth of ileal crypts and reduced intestinal bacterial proteolysis (40). Studies showed that compared to the control, 250 or 500 $\mathrm{mg} / \mathrm{kg}$ sweet chestnut tannin had no obvious effects on body weight and feed conversion in 41-day-old chickens. However, in 28 -day-old chickens, $1,000 \mathrm{mg} / \mathrm{kg}$ tannins reduced the numbers of $E$. coli and other harmful bacteria in the small intestine. It has also been observed that tannins change the microorganism population quantity in the small intestine and colon in chickens (41). An experiment based on broilers investigated the effect of different concentrations of phenolic compounds from grape pomace (GP). The work showed that grape pomace might delay meat lipid oxidation, which was linked to an increase in the meat polyunsaturated fatty acid (PUFA) concentration (42). A hydrolyzable tannin extracted from chestnut was tested for efficacy in regulating the proliferation of Clostridium perfringens in the gut. The results showed that even at low concentrations $(1.5-3.0 \mathrm{~g} / \mathrm{kg})$, chestnut tannins had a remarkable effect on controlling necrotic enteritis (NE). Compared to the control group, proliferation of Clostridium perfringens and gut damage were reduced by tannins in the treatment groups (11). Experimental studies on pigs demonstrated the effects of two compounds containing tannins. The gastrointestinal absorption of mycotoxins was reduced by grape pomace, which would be considered an alternative to commercial products. Gold grape seed extract (GSE) caused an ecological shift in the microbiome, significantly increasing the numbers of Lachnospiraceae, Clostridales, Lactobacillus, and Ruminococcaceae. This might be due to the bacterial populations or the structures of the compounds in the colon $(43,44)$. Based on the above results, tannins represent a potential alternative strategy to antibiotics in animal production. However, suppression of intracellular bacteria is also important (45) and needs to be further studied in plant tannins. Further investigation is necessary to determine the effects of tannins on bacterial conditions in vitro (46).

A bacteriostatic model was used to study the mechanism of tannins. Condensed tannins (CT) from purple prairie clover (Dalea purpurea Vent; PPC) were screened for antiEscherichia coli O157:H7 activity against $E$. coli O157:H7 strain 3,081 . After $24 \mathrm{~h}$, optical density was measured to assess the growth of the bacteria at $600 \mathrm{~nm}$. CT increased the lag time and reduced the growth rate of E. coli O157:H7. At the same time, CT decreased the proportions of unsaturated fatty acids in the total fatty acids and disrupted the outer membrane structure. The results showed that the possible mechanism was associated with fatty acid composition and the outer membrane of the cell (47). Synthesizing each index showed that tannins exert bacteria by inhibiting extracellular microbial enzymes and oxidative phosphorylation, which directly affects microbial metabolism, depriving microorganisms of substrates needed for growth and increasing membrane permeability (48).

It has been reported that the amount of hydroxyl groups in tannins and the release of hydrogen peroxide are important indicators to evaluate the antibacterial properties, which are positively correlated with antioxidant properties. For instance, trihydroxy b-cycloflavonol (gallic catechin) has stronger effects on Streptococcus, Clostridium, and Staphylococcus than dihydroxy b-cyclocatechin $(43,49)$. Because tannins come from a wide range of sources and have diverse antibacterial effects, screening and identifying tannins that are effective and specific to target microorganisms will be the work of ongoing research.

\section{Antiviral Activity}

Some papers have reported that tannins have the ability to prevent viral infection such as HIV, bovine adeno-associated virus (BAAV) and norovirus. An herb screening model based on saliva-based binding/blocking assays using the NoV P protein was developed, and tannic acid was identified as a strong inhibitor in the binding of NoV to HBGA receptors. The data suggested that tannic acid (TA) is a promising antiviral agent against NoVs (50). Another study on TA and BAAV found that treatment with TA reduced BAAV transcytosis and increased lung transduction. The sorting and activity of the BAAV-expressed cystic fibrosis transmembrane regulator membrane protein were not impaired by TA (51). The inhibitory activity of tannins on HIV-1 was tested, and the results indicated that tannins inhibited syncytia formation, lytic effects, viral p24 antigen production and the activity of the HIV-1 reverse transcriptase (RT) enzyme (52). Another study on HIV-I integrase activity showed that some herb extracts display strong inhibition of integrase activity. The effect was most likely due to tannins in herb extracts (53). According to data from these studies, tannins are an effective compound against HIV-1 with high potential for further studies (54). In addition to the above viruses, tannins also inhibited other types of viruses, such as enterovirus. Research in mice demonstrated that chebulagic acid, as a hydrolyzable tannin, reduced the viral cytopathic effect on rhabdomyosarcoma cells. By inhibiting viral replication, chebulagic acid may reduce the mortality induced by a lethal dose of enterovirus 71 and relieve clinical symptoms (55). The beneficial effect was also reflected in the inhibition of hepatitis virus. In vitro, the results showed that (2)-epigallocatechin-3-gallate (EGCG) from green tea acted directly on hepatitis C virus (HCV) and prevented the virus from entering the cell surface (56). The same results were obtained in Huh7.5 cells, in which tannic acid, a polymer of gallic acid and glucose molecules, blocked cell-to-cell spread in infectious HCV cell cultures but did not inhibit HCV replication after infection (57). Hepatitis B virus (HBV) infection remains a major global health problem. In this study, hydrolyzable tannins such as 
punicalagin, punicalin, and geraniin reduced the production of $\mathrm{HBeAg}$ and the accumulation of cccDNA in HepDES19 and HepG2.117 cells. These hydrolyzable tannins may serve as new agents or strategies to block HBV infection (58). A study investigated the antiviral effects of tannins on 12 different viruses (enveloped and non-enveloped viruses). Extracts from persimmon showed strong antiviral effects against various viruses. Other tannins derived from green tea, acacia and gallnuts were effective against some viruses. Tannins interact with virion proteins, and restricted virus adsorption to the cells may be the possible mechanism of the inhibitory effect of tannins (59).

In summary, the antiviral function of tannins is realized through inhibiting the invasion of cells and nuclei by viruses, the activity of virus reverse transcriptase, and the transmission to other cells and promoting viral protein denaturation. However, due to their different sources and chemical structures, tannins have different antiviral properties.

\section{Antiparasitic Activity}

Parasitic infections represent a major pathological threat to livestock and poultry production. Tannins represent a valuable option as an alternative to drugs for the control of parasites. In vitro bioassays evaluated the effects of condensed tannins (CTs) obtained from Lotus pedunculatus (LP), Lotus corniculatus (LC), Dorycnium pentaphyllum (DP), Dorycnium rectum (DR), and Rumex obtusifolius (RO) on egg hatching, larval development and the viability of Teladorsagia circumcincta (Stadelmann, 1894) (Ostertagia circumcincta) and the L3 larvae of Trichostrongylus colubriformis (Giles, 1892). These studies showed that CTs were able to inhibit egg hatching, slow larval development, kill undeveloped larvae and disrupt the life cycle of nematodes (60-62). Some experiments evaluated the anthelmintic effects of extracts from tropical tanniniferous plants (TTPs), such as Acacia pennatula, Lysiloma latisiliquum, Piscidia piscipula and Leucaena leucocephala, on Haemonchus contortus. These results suggested that tannins may be used as anthelmintics for gastrointestinal nematodes by interfering with the process of L (3) exsheathment $(63,64)$.

In addition, condensed tannins showed activity against freeliving larvae and parasitic adults, confirming the potential role of tannins in the control of parasites at different growth phases $(65,66)$. In summary, the direct mechanisms involve restricting larval development to reduce the establishment of infected thirdstage larvae in the host and decreasing spawning to inhibit the motion performance of the parasite, and the indirect mechanisms involve improving human immune function and resistance to infection. However, many factors influence the impact of tannins, such as plant sources of different varieties, the growth stage of parasites and the different host species.

\section{Anti-inflammatory Activity}

Recently, some studies found that plant tannins have antiinflammatory effects by inhibiting $\mathrm{NO}$ and prostaglandin-E2 (PGE2) (67). Most tannin extracted from different plants display anti-inflammatory functions. An in vitro assay using obese Zucker rats applied grape seed procyanidin extract to demonstrate that it can reduce obesity-induced inflammation by mediating the expression of cytokines (68). In addition, the tannin fraction of the extract from black raspberry seeds has anti-inflammatory activity to reduce nitric oxide (NO) induced by lipopolysaccharide (LPS) in RAW 264.7 cells (69). The anti-inflammatory function has also been demonstrated in croton oil-induced ear edema mice. In this study, hydrolyzable tannins from Myricaria bracteata showed a significant anti-inflammatory effect on mice (70). Tannins can form a gastroprotective barrier to improve gastritis symptoms based on their antioxidant activity (39).

Therefore, it is speculated that the anti-inflammatory properties of tannins from different sources may be caused by regulating cytokine expression, reducing the production of inflammatory substances and enhancing complexation with other molecules. However, the mechanism remains to be explored because animal experiments are still lacking.

\section{Antidiarrheal Activity}

Plant tannins have shown antidiarrheal potential in animal models. A study performed by Bonelli et al. (71) shown that administration of tannins in calves with diarrhea may shorten the duration of the diarrheic episode (DDE). This research shows that some plant tannins have anti-diarrhea effects. In a mouse model of diarrhea induced by castor oil, Galla Chinensis oral solution (GOS) showed significant antidiarrheal activity, suggesting that GOS can be used to complement other therapies because it is an effective and stable antidiarrheal drug (72). In piglets, an experimental model for post-weaning diarrhea with enterotoxigenic Escherichia coli F4 (ETEC F4) was established, and then the effect of chestnut-tannin (1\%) in preventing diarrhea was assessed. Tannins reduced the diarrhea rate and the duration of diarrhea (73). A study examined the effects of a hydrolyzable tannin extracted from Chinese gallnut (penta-m-digalloyl-glucose, PDG) on mouse diarrhea. The results showed that intraluminal injection of PDG reduced cholera toxin-induced intestinal fluid secretion (74). Overall, tannins are effective antidiarrhea compounds, and they may provide a new therapeutic intervention for diarrhea in animal production.

\section{CONCLUSION AND FUTURE PERSPECTIVES}

As a natural polyphenolic substance, plant tannins have been found to have a variety of biological functions. The potential utility of plant tannins as feed additives is enormous in animal production. However, the addition of high tannins in animal diet needs to be very cautious.it may adversely affect the growth and development of animals and induce metabolic disorders, which may depend on the type and chemical structure of tannins, intake, dietary composition and animal species. In addition, different extraction sources and concentrations of plant tannins, as well as different 
animal species and physiological statuses, will influence the additive effect. At present, studies on the structure and nutritional characteristics of plant tannins are not sufficient. Most of the research has focused on complex plant tannins, while there have been few studies on the effects of single plant tannins. Meanwhile, cross-disciplinary studies are also insufficient, resulting in some conclusions still being limited to speculation. The mechanism of action is not yet clear. More studies should focus on the main active components, structural characteristics and mechanisms of plant tannins from different sources to ensure the accurate application of plant tannins in animal production. Further research is needed in the future.

\section{REFERENCES}

1. Xiao Y, Zhang S, Tong H, Shi S. Comprehensive evaluation of the role of soy and isoflavone supplementation in humans and animals over the past two decades. Phytother Res. (2018) 32:384-94. doi: 10.1002/ptr. 5966

2. Hu Y, Wang L, Shao D, Wang Q, Wu Y, Han Y, et al. Selectived and reshaped early dominant microbial community in the cecum with similar proportions and better homogenization and species diversity due to organic acids as AGP alternatives mediate their effects on broilers growth. Front Microbiol. (2019) 10:2948. doi: $10.3389 /$ fmicb.2019.02948

3. Zhang S, Zhong G, Shao D, Wang Q, Hu Y, Wu T, et al. Dietary supplementation with Bacillus subtilis promotes growth performance of broilers by altering the dominant microbial community. Poult Sci. (2021) 100:100935. doi: 10.1016/j.psj.2020.1 2.032

4. Shen Y, Zhang S, Zhao X, Shi S. Evaluation of a lecithin supplementation on growth performance, meat quality, lipid metabolism, and cecum microbiota of broilers. Animals (Basel). (2021) 11:2537. doi: 10.3390/ani110 92537

5. Patra AK, Saxena J. Exploitation of dietary tannins to improve rumen metabolism and ruminant nutrition. J Sci Food Agric. (2011) 91:2437. doi: $10.1002 /$ jsfa. 4152

6. Aboagye IA, Oba M, Koenig KM, Zhao GY, Beauchemin KA. Use of gallic acid and hydrolyzable tannins to reduce methane emission and nitrogen excretion in beef cattle fed a diet containing alfalfa silage 1,2. J Anim Sci. (2019) 97:2230-44. doi: 10.1093/jas/skz101

7. Treviño J, Ortiz L, Centeno C. Effect of tannins from faba beans (Vicia faba) on the digestion of starch by growing chicks. Anim Feed Sci Technol. (1992) 37:345-9. doi: 10.1016/0377-8401(92)90017-Z

8. Smulikowska S, Pastuszewska B, Święch E, Ochtabińska A, Buraczewska L. Tannin content affects negatively nutritive value of pea for monogastrics. $J$ Anim Feed Sci. (2001) 10:511-23. doi: 10.22358/jafs/68004/2001

9. Schiavone A, Guo K, Tassone S, Gasco L, Hernandez E, Denti R, et al. Effects of a natural extract of chestnut wood on digestibility, performance traits, and nitrogen balance of broiler chicks. Poul Sci. (2008) 87:5217. doi: $10.3382 /$ ps.2007-00113

10. Parys AV, Boyen F, Dewulf J, Haesebrouck F, Pasmans F. The use of tannins to control salmonella typhimurium infections in pigs. Zoonoses Public Health. (2010) 57:423-8. doi: 10.1111/j.1863-2378.2009.01242.x

11. Tosi G, Massi P, Antongiovanni M, Buccioni A, Minieri S, Marenchino L, et al. Efficacy test of a hydrolysable tannin extract against necrotic enteritis in challenged broiler chickens. Italian J Anim Sci. (2013) 12:e62. doi: 10.4081/ijas.2013.e62

12. Bilić-Šobot D, Kubale V, Škrlep M, Candek-Potokar M, Prevolnik Povše M, Fazarinc G. Effect of hydrolysable tannins on intestinal morphology, proliferation and apoptosis in entire male pigs. Arch Anim Nutr. (2016) 70:378-88. doi: 10.1080/1745039X.2016.1206735

13. Haslam EJ. Plant Polyphenols: Vegetable Tannins Revisited (1989). Cambridge: Cambridge University Press (1989).

\section{AUTHOR CONTRIBUTIONS}

ZT wrote this manuscript. WH and XF collected literature. AG reviewed the manuscript and given critical suggestions and comments. All authors read and approved the final manuscript.

\section{FUNDING}

This work was supported by the Scientific and Technological Innovation Team Construction Project for Protection and Utilization of Under-Forest Biological Resources in Universities of Yunnan Province.
14. Mcsweeney CS, Palmer B, Mcneill DM, Krause DO. Microbial interactions with tannins: nutritional consequences for ruminants. Anim Feed Sci Tech. (2001) 91:83-93. doi: 10.1016/S0377-8401(01) 00232-2

15. Yoshiki K, Nonaka G, Nishioka I, Chang JJ, Lee KH. Antitumor agents, 129. Tannins and related compounds as selective cytotoxic agents. J Nat Prod. (1992) 55:1033-43. doi: 10.1021/np50086a002

16. Nonaka GI, Nishimura H, Nishioka I. Tannins and related compounds. Part 26 isolation and structures of stenophyllanins A, B, and C, novel tannins from Quercus stenophylla. J Chem Soc Perkin Trans 1. (1985) 16:32237. doi: $10.1002 /$ chin. 198517318

17. Hiroaki N, Gen-Ichiro N, Nishioka I. Scyllo-quercitol gallates and hexahydroxydiphenoates from Quercus stenophylla. Phytochemistry. (1986) 25:2599-604. doi: 10.1016/S0031-9422(00)84517-3

18. Khanbabaee K, van Ree T. Tannins: classification and definition. Nat Prod Rep. (2001) 18:641-9. doi: 10.1039/b101061l

19. Berard NC, Wang Y, Wittenberg KM, Krause DO, Coulman BE, Mcallister $\mathrm{TA}$, et al. Condensed tannin concentrations found in vegetative and mature forage legumes grown in western Canada. Can J Plant Sci. (2015) 91:66975. doi: $10.4141 /$ cjps 10153

20. Kyamuhangire W, Krekling T, Reed E, Pehrson RJ. The microstructure and tannin content of banana fruit and their likely influence on juice extraction. J Sci Food Agric. (2010) 86:1908-15. doi: 10.1002/jsfa. 2553

21. Sarneckis CJ, Dambergs B, Jones, P, Mercurio M, Smith PA, et al. Quantification of condensed tannins by precipitation with methyl cellulose: development and validation of an optimised tool for grape and wine analysis. Aust J Grap Wine Res. (2010) 12:39-49. doi: 10.1111/j.1755-0238.2006.tb00042.x

22. Ortiz J, Marin-Arroyo MR, Noriega-Dominguez MJ, Navarro M, Arozarena I. Color, phenolics, and antioxidant activity of blackberry (Rubus glaucus Benth.), blueberry (Vaccinium floribundum Kunth.), and apple wines from ecuador. J Food Sci. (2013) 78:C985-93. doi: 10.1111/1750-3841.1 2148

23. Figueroa-Espinoza MC, Zafimahova A, Alvarado P, Dubreucq E, Poncet-Legrand C. Grape seed and apple tannins: emulsifying and antioxidant properties. Food Chem. (2015) 178:3844. doi: 10.1016/j.foodchem.2015.01.056

24. Terrill T, Rowan AM, Douglas GB, Barry TN. Determination of extractable and bound condensed tannin concentrations in forage plants, protein concentrate meals and cereal grains. J Sci Food Agric. (2010) 58:3219. doi: 10.1002/jsfa.2740580306

25. Jin L, Wang Y, Iwaasa AD, Xu Z, Schellenberg MP, Zhang YG, et al. Effect of condensed tannins on ruminal degradability of purple prairie clover (Dalea purpurea Vent.) harvested at two growth stages. Anim Feed Sci Technol. (2012) 176:17-25. doi: 10.1016/j.anifeedsci.2012.07.003

26. Li Y, Iwaasa A, Wang Y, Jin L, Han G, Zhao M, et al. Condensed tannins concentration of selected prairie legume forages as affected by phenological stages during two consecutive growth seasons in western Canada. Can J Plant Sci. (2014) 94:817-26. doi: 10.4141/cjps2013-234 
27. Lall RK, Syed DN, Adhami VM, Khan MI, Mukhtar H. Dietary polyphenols in prevention and treatment of prostate cancer. Int J Mol Sci. (2015) 16:3350-76. doi: 10.3390/ijms1602 3350

28. Squillaro T, Cimini A, Peluso G, Giordano A, Melone MAB. Nano-delivery systems for encapsulation of dietary polyphenols: an experimental approach for neurodegenerative diseases and brain tumors. Biochem Pharmacol. (2018) 154:303-17. doi: 10.1016/j.bcp.2018.05.016

29. Tuyen PT, Xuan TD, Khang DT, Ahmad A, Quan NV, Tu Anh TT, et al. Phenolic compositions and antioxidant properties in bark, flower, inner skin, kernel and leaf extracts of castanea crenata sieb. et Zucc. Antioxidants (Basel). (2017) 6:31. doi: 10.3390/antiox602 0031

30. Peng $\mathrm{K}, \mathrm{Xu} \mathrm{Z}$, Nair J, Jin L, McAllister TA, Acharya S, et al. Conserving purple prairie clover (Dalea purpurea Vent.) as hay and silage had little effect on the efficacy of condensed tannins in modulating ruminal fermentation in vitro. J Sci Food Agric. (2021) 101:1247-54. doi: 10.1002/jsfa. 10913

31. De ng Y-T, Liang G, Shi Y, Li HL, Zhang J, Mao XM, et al. Condensed tannins from Ficus altissima leaves: Structural, antioxidant, and antityrosinase properties. Process Biochem. (2016) 51:1092-9. doi: 10.1016/j.procbio.2016.04.022

32. Luciano G, Vasta V, Monahan FJ, Lopez-Andres P, Biondi L, Lanza M, et al. Antioxidant status, colour stability and myoglobin resistance to oxidation of longissimus dorsi muscle from lambs fed a tannin-containing diet. Food Chem. (2011) 124:1036-42. doi: 10.1016/j.foodchem.2010.07.070

33. Chen S, Liu Y, Zhi Y, Zhao Y, Zhang B, Xinxi GU, et al. Effects of tannic acid on fur quality, immune organ development and antioxidant capacity of growing rex rabbits. Chin J Anim Nutr. (2019) 31:5151-56. doi: 10.3969/j.issn.1006-267x.2019.11.030

34. Farahat MH, Abdallah FM, Ali HA, Hernandez-Santana A. Effect of dietary supplementation of grape seed extract on the growth performance, lipid profile, antioxidant status and immune response of broiler chickens. Animal. (2017) 11:771-7. doi: 10.1017/S1751731116002251

35. Gülçin L, Huyut Z, Elmasta M, Aboul-Enein HY. Radical scavenging and antioxidant activity of tannic acid. Arab J Chem. (2010) 3:4353. doi: 10.1016/j.arabjc.2009.12.008

36. Toshiaki A, Koshiyama I, Fukushima D. Antioxidative properties of procyanidins B-1 and B-3 from azuki beans in aqueous systems. Agric Biol Chem. (1988) 52:2717-22. doi: 10.1080/00021369.1988.10869144

37. Olejar KJ, Ray S, Kilmartin PA. Enhanced antioxidant activity of polyolefin films integrated with grape tannins. J Sci Food Agric. (2016) 96:282531. doi: 10.1002/jsfa.7450

38. López-Andrés P, Luciano G, Vasta V, Gibson TM, Mueller-Harvey I. Dietary quebracho tannins are not absorbed, but increase the antioxidant capacity of liver and plasma in sheep. Br J Nutr. (2013) 110. doi: 10.1017/S0007114512005703

39. Demarque DP, Callejon DR, de Oliveira G, Silva DB, Carollo CA, Lopes NP. The role of tannins as antiulcer agents: a fluorescence-imaging based study. Rev Bras Farmacogn. (2018) 28:S0102695X18300899. doi: 10.1016/j.bjp.2018.03.011

40. Biagia G, Cipollini I, Paulicks BR, Roth FX. Effect of tannins on growth performance and intestinal ecosystem in weaned piglets. Arch Anim Nutr. (2010) 64:121-35. doi: 10.1080/1745039090346 1584

41. Jamroz D, Wiliczkiewicz A, Skorupinska J, Orda J, Kuryszko J, Tschirch H. Effect of sweet chestnut tannin (SCT) on the performance, microbial status of intestine and histological characteristics of intestine wall in chickens. Br Poult Sci. (2009) 50:687-99. doi: 10.1080/00071660903191059

42. Chamorro S, Viveros A, Rebole A, Rica BD, Arija I, Brenes A. Influence of dietary enzyme addition on polyphenol utilization and meat lipid oxidation of chicks fed grape pomace. Food Research International. (2015) 73:197203. doi: 10.1016/j.foodres.2014.11.054

43. Choy YY, Quifer-Rada P, Holstege DM, Frese SA, Calvert CC, Mills DA, et al. Phenolic metabolites and substantial microbiome changes in pig feces by ingesting grape seed proanthocyanidins. Food Funct. (2014) 5:2298-308. doi: 10.1039/C4FO00 325J
44. Gambacorta L, Pinton P, Avantaggiato G, Oswald IP, Solfrizzo M. Grape pomace, an agricultural byproduct reducing mycotoxin absorption: in vivo assessment in pig using urinary biomarkers. J Agric Food Chem. (2016) 64:6762-71. doi: 10.1021/acs.jafc.6b02146

45. Shi S, Wu S, Shen Y, Zhang S, Xiao Y, He X, et al. Iron oxide nanozyme suppresses intracellular Salmonella Enteritidis growth and alleviates infection in vivo. Theranostics. (2018) 8:6149-62. doi: 10.7150/thno. 29303

46. Brus M, Gradisnik L, Trapecar M, Skorjanc D, Frangez R Beneficial effects of water-soluble chestnut (Castanea sativa Mill.) tannin extract on chicken small intestinal epithelial cell culture. Poult Sci. (2018) 97:1271-82. doi: 10.3382/ps/pe $\mathrm{x} 424$

47. Wang Y, Jin L, Ominski KH, He M, Xu Z, Krause DO, et al. Screening of condensed tannins from Canadian prairie forages for anti-Escherichia coli O157:H7 with an emphasis on purple prairie clover (Dalea purpurea Vent). J Food Prot. (2013) 76:560-7. doi: 10.4315/0362-028X.JFP-12-259

48. Liu XL, Hao YQ, Jin L, Xu ZJ, McAllister TA, Wang Y. Anti-Escherichia coli O157:H7 properties of purple prairie clover and sainfoin condensed tannins. Molecules. (2013) 18:2183-99. doi: 10.3390/molecules18022183

49. Anita P, Sivasamy S, Madan Kumar PD, Balan IN, Ethiraj S. In vitro antibacterial activity of Camellia sinensis extract against cariogenic microorganisms. J Basic Clin Pharm (2014) 6:35-9. doi: 10.4103/0976-0105.14 5777

50. Zhang XF, Dai YC, Zhong W, Tan M, Lv ZP, Zhou YC, et al. Tannic acid inhibited norovirus binding to HBGA receptors, a study of 50 Chinese medicinal herbs. Bioorg Med Chem. (2012) 20:161623. doi: 10.1016/j.bmc.2011.11.040

51. Di Pasquale G, Ostedgaard L, Vermeer D, Swaim WD, Karp P, Chiorini JA. Bovine AAV transcytosis inhibition by tannic acid results in functional expression of CFTR in vitro and altered biodistribution in vivo. Gene Ther. (2012) 19:576-81. doi: 10.1038/gt.2011.138

52. Karadeniz F, Kang KH, Park JW, Park SJ, Kim SK. Anti-HIV1 activity of phlorotannin derivative 8,4"'-dieckol from Korean brown alga Ecklonia cava. Biosci Biotechnol Biochem. (2014) 78:1151-8. doi: 10.1080/09168451.2014.923282

53. Au TK, Lam TL, Ng TB, Fong WP, Wan DC. A comparison of HIV-1 integrase inhibition by aqueous and methanol extracts of Chinese medicinal herbs. Life Sci. (2001) 68:1687-94. doi: 10.1016/S0024-3205(01)00945-6

54. Tietjen I, Ntie-Kang F, Mwimanzi P, Onguene PA, Scull MA, Idowu TO, et al. Screening of the Pan-African natural product library identifies ixoratannin A-2 and boldine as novel HIV-1 inhibitors. PLoS ONE. (2015) 10:e0121099. doi: 10.1371/journal.pone.0121099

55. Yang Y, Xiu J, Liu J, Zhang L, Li X, Xu Y, et al. Chebulagic acid, a hydrolyzable tannin, exhibited antiviral activity in vitro and in vivo against human enterovirus 71. Int J Mol Sci. (2013) 14:9618-27. doi: 10.3390/ijms14059618

56. Calland N, Albecka A, Belouzard S, Wychowski C, Duverlie G, Descamps V, et al. (-)-Epigallocatechin-3-gallate is a new inhibitor of hepatitis C virus entry. Hepatology. (2012) 55:720-9. doi: 10.1002/hep.2 4803

57. Liu S, Chen R, Hagedorn $\mathrm{CH}$. Tannic acid inhibits hepatitis C virus entry into Huh7.5 cells. PLoS ONE. (2015) 10:e0131358. doi: 10.1371/journal.pone.0131358

58. Liu C, Cai D, Zhang L, Tang W, Yan R, Guo H, et al. Identification of hydrolyzable tannins (punicalagin, punicalin and geraniin) as novel inhibitors of hepatitis B virus covalently closed circular DNA. Antiviral Res. (2016) 134:97-107. doi: 10.1016/j.antiviral.2016.08.026

59. Ueda K, Kawabata R, Irie T, Nakai Y, Tohya Y, Sakaguchi T. Inactivation of pathogenic viruses by plant-derived tannins: strong effects of extracts from persimmon (Diospyros kaki) on a broad range of viruses. PLoS ONE. (2013) 8:e55343. doi: 10.1371/journal.pone.0055343

60. Minho AP, Gennari SM, Amarante AFTD, Ab Dala AL. Anthelmintic effects of condensed tannins on Trichostrongylus colubriformis in experimentally infected sheep. Semina Ciências Agrárias. (2010) 31:1009-16. doi: 10.5433/1679-0359.2010v31n4p1009

61. Molan AL, Faraj AM. The effects of condensed tannins extracted from different plant species on egg hatching and larval development of Teladorsagia 
circumcincta (Nematoda: Trichostrongylidae). Folia Parasitol (Praha). (2010) 57:62-8. doi: 10.14411/fp.2010.008

62. Molan AL. Effect of purified condensed tannins from pine bark on larval motility, egg hatching and larval development of Teladorsagia circumcincta and Trichostrongylus colubriformis (Nematoda: Trichostrongylidae). Folia Parasitol (Praha). (2014) 61:371-6. doi: 10.14411/fp.2014.036

63. Alonso-Diaz MA, Torres-Acosta JF, Sandoval-Castro CA, Aguilar-Caballero AJ, Hoste H. In vitro larval migration and kinetics of exsheathment of Haemonchus contortus larvae exposed to four tropical tanniniferous plant extracts. Vet Parasitol. (2008) 153:313-9. doi: 10.1016/j.vetpar.2008.01.042

64. Oliveira LM, Bevilaqua CM, Macedo IT, Morais SM, Monteiro MV, Campello CC, et al. Effect of six tropical tanniferous plant extracts on larval exsheathment of Haemonchus contortus. Rev Bras Parasitol Vet. (2011) 20:155-60. doi: 10.1590/S1984-29612011000200011

65. Hoste H, Martinez-Ortiz-De-Montellano C, Manolaraki F, Brunet S, OjedaRobertos N, Fourquaux I, et al. Direct and indirect effects of bioactive tannin-rich tropical and temperate legumes against nematode infections. Vet Parasitol. (2012) 186:18-27. doi: 10.1016/j.vetpar.2011.11.042

66. Desrues O, Fryganas C, Ropiak HM, Mueller-Harvey I, Enemark HL, Thamsborg SM. Impact of chemical structure of flavanol monomers and condensed tannins on in vitro anthelmintic activity against bovine nematodes. Parasitology. (2016) 143:444-54. doi: 10.1017/S003118201500 1912

67. Wijesinghe W, Ahn G, Lee WW, Kang MC, Kim EA, Jeon YJ. Anti-inflammatory activity of phlorotannin-rich fermented Ecklonia cava processing by-product extract in lipopolysaccharidestimulated RAW 264.7 macrophages. J Appl Phycol. (2013) 25:1207-13. doi: 10.1007/s10811-012-9939-5

68. Pallarès V, Cedó L, Castell-Auví A, Pinent M, Ardévol A, Arola L, et al. Effects of grape seed procyanidin extract over low-grade chronic inflammation of obese Zucker fa/fa rats. Food Res Int. (2013) 53:31924. doi: 10.1016/j.foodres.2013.05.006

69. Park M, Cho H, Jung H, Lee H, Hwang KT. Antioxidant and antiinflammatory activities of tannin fraction of the extract from black raspberry seeds compared to grape seeds. J Food Biochem. (2014) 38:25970. doi: $10.1111 / \mathrm{jfbc} .12044$
70. Liu JB, Ding YS, Zhang Y, Chen JB, Cui BS, Bai JY, et al. Anti-inflammatory Hydrolyzable Tannins from Myricaria bracteata. J Nat Prod. (2015) 78:101525. doi: $10.1021 / \mathrm{np} 500953 \mathrm{e}$

71. Bonelli F, Turini L, Sarri G, Serra A, Buccioni A, Mele M. Oral administration of chestnut tannins to reduce the duration of neonatal calf diarrhea. BMC Vet Res. (2018) 14:227. doi: 10.1186/s12917-018-1549-2

72. Yang $\mathrm{Y}$, Luo $\mathrm{H}$, Song $\mathrm{X}$, Yu L, Xie J, Yang J, et al. Preparation of galla chinensis oral solution as well as its stability, safety, and antidiarrheal activity evaluation. Evid Based Complement Alternat Med. (2017) 2017:1851459. doi: 10.1155/2017/1851459

73. Girard M, Thanner S, Pradervand N, Hu D, Ollagnier C, Bee G. Hydrolysable chestnut tannins for reduction of postweaning diarrhea: efficacy on an experimental ETEC F4 model. PLoS ONE. (2018) 13:e0197878. doi: 10.1371/journal.pone.019878

74. Wongsamitkul N, Sirianant L, Muanprasat C, Chatsudthipong V. A plant-derived hydrolysable tannin inhibits CFTR chloride channel: a potential treatment of diarrhea. Pharm Res. (2010) 27:490-7. doi: 10.1007/s11095-009-0040-y

Conflict of Interest: The authors declare that the research was conducted in the absence of any commercial or financial relationships that could be construed as a potential conflict of interest.

Publisher's Note: All claims expressed in this article are solely those of the authors and do not necessarily represent those of their affiliated organizations, or those of the publisher, the editors and the reviewers. Any product that may be evaluated in this article, or claim that may be made by its manufacturer, is not guaranteed or endorsed by the publisher.

Copyright $\odot 2022$ Tong, He, Fan and Guo. This is an open-access article distributed under the terms of the Creative Commons Attribution License (CC BY). The use, distribution or reproduction in other forums is permitted, provided the original author(s) and the copyright owner(s) are credited and that the original publication in this journal is cited, in accordance with accepted academic practice. No use, distribution or reproduction is permitted which does not comply with these terms. 